\title{
Development and Application of Cell-Phone-Based Internet of Things (IoT) Systems for Soil Moisture Monitoring
}

\author{
José 0. Payero ${ }^{1 *}$, Michael W. Marshall1 ${ }^{1}$ (D), Bhupinder S. Farmaha1, Rebecca Hitchcock Davis ${ }^{1}$, \\ Ali Mirzakhani Nafchi² \\ ${ }^{1}$ Clemson University Edisto Research and Education Center, Blackville, USA \\ ${ }^{2}$ Cornell University, New York, USA \\ Email: *jpayero@clemson.edu
}

How to cite this paper: Payero, J.O., Marshall, M.W., Farmaha, B.S., Davis, R.H. and Nafchi, A.M. (2021) Development and Application of Cell-Phone-Based Internet of Things (IoT) Systems for Soil Moisture Monitoring. Agricultural Sciences, 12, 549564.

https://doi.org/10.4236/as.2021.125035

Received: April 15, 2021

Accepted: May 17, 2021

Published: May 20, 2021

Copyright $\odot 2021$ by author(s) and Scientific Research Publishing Inc. This work is licensed under the Creative Commons Attribution International License (CC BY 4.0).

http://creativecommons.org/licenses/by/4.0/

\begin{abstract}
Active soil moisture monitoring is an important consideration in irrigation water management. A permanent and readily accessible record of changes in soil moisture can be used to improve future water management decisionmaking. Similarly, accessing stored soil moisture data in near-real-time is also essential for making timely farming and management decisions, such as where, when, and how much irrigation to apply. Access to reliable communication systems and delivery of real-time data can be affected by its availability near production fields. Therefore, soil moisture monitoring systems with realtime data functionality that can meet the needs of farmers at an affordable cost are currently needed. The objective of the study was to develop and fieldtest affordable cell-phone-based Internet of things (IoT) systems for soil moisture monitoring. These IoT systems were designed using low-cost hardware components and open-source software to transmit soil moisture data from the Watermark 200SS or $\mathrm{ECH}_{2} \mathrm{O}$ EC-5 sensors. These monitoring systems utilized either Particle Electron or Particle Proton Arduino-compatible devices for data communication. The IoT soil moisture monitoring systems have been deployed and operated successfully over the last three years in South Carolina.
\end{abstract}

\section{Keywords}

Soil Moisture, Internet of Things, IoT, Arduino, Sensors, Irrigation

\section{Introduction}

Soil moisture is an essential component of the hydrological, agricultural, ecolog- 
ical, and environmental cycles. It affects land-atmosphere interactions, the exchange of water and energy fluxes, rainfall-runoff processes, net ecosystem exchange, and food security [1]. It also plays a significant role in affecting critical physical processes in numerical weather prediction, climate modeling, agricultural crop growth modeling, and flood forecasting [2]. Soil moisture is an essential component of the hydrologic cycle and a critical variable for optimizing efficient irrigation water management in agriculture [3]. Therefore, obtaining accurate real-time estimates of spatial and temporal variations in soil moisture are critical [4]. Significant effort has been devoted to soil moisture measurement using various techniques, including manual in-situ estimation, automated insitu sensing networks, numerical modeling, and remote sensing applications [1].

Researchers have used in-situ sensing sites or networks to measure, record, and transmit soil moisture data from many locations worldwide [1]. For example, traditional sensing technologies that measure soil moisture include the neutron probe [5], time-domain reflectometry (TDR) [6] [7], frequency-domain reflectometry (FDR) [8], capacitance [2] [9] [10], and heat dissipation [11]. However, researchers have used other emerging in-situ and proximal sensing techniques, such as cosmic-ray neutrons [1] [12], global positioning system (GPS) signals [1] [13], Global Navigation Satellite System (GNSS) [3], and distributed temperature sensing (DTS) [1] [14] [15] [16].

There have been significant advances in the large-scale estimation of soil moisture from remote sensing using measurements from optical, thermal, passive, and active microwave sensors [4]. Satellite-based large-scale soil moisture monitoring includes the Soil Moisture and Ocean Salinity Mission (SMOS), Soil Moisture Active Passive Mission (SMAP), Airborne Microwave Observatory of Subcanopy and Subsurface Mission (AirMOSS) [1], Sentinel-1 [3] [17], and Moderate-Resolution Imaging Spectroradiometer (MODIS) [18]. However, at the local field level, there are still limitations to using satellite-based remote sensing soil moisture data for irrigation management, including limited surface penetration, cloud interference, perturbation by meteorological conditions and vegetation and surface roughness, and low spatial and temporal resolution [1] [4].

Despite the existence of in-situ soil moisture monitoring networks in some areas and the promise of new soil moisture products derived from remote sensing, farmers need information at the field scale with near-real-time data for daily irrigation decisions. There is also a need for simple and affordable systems to collect and transmit soil moisture data from agricultural fields. Recent advances in low-cost open-source electronics, wireless communication, and the Internet of things (IoT) technologies provide new opportunities for agricultural soil moisture monitoring [19]. Many researchers from around the world are currently developing systems to address these shortcomings. For example, researchers have created different IoT systems for soil moisture monitoring in China [20] [21], India [22] [23] [24], Japan [25], and the United States [26] [27]. Therefore, the 
objective of this study was to develop and field-test affordable cell-phone-based Internet of things (IoT) systems for soil moisture monitoring. These end-use IoT systems would be accurate, affordable for small farmers, robust under normal field conditions, reliable, and easy to use.

\section{Methods}

\subsection{Research Site Description}

Field and laboratory studies were conducted at the Clemson University Edisto Research and Education Center (EREC) near Blackville, SC (33 $21^{\prime} 51.21 \mathrm{~N}$, $\left.81^{\circ} 19^{\prime} 45.74 \mathrm{~W}\right)$. The research site is located in the humid southeast USA, which receives an average annual precipitation of $1198 \mathrm{~mm}$ [28]. Despite the high rainfall, irrigation is an essential component of agricultural production in South Carolina due to the uneven rainfall distribution during the growing season and coarse-textured soils with low water-holding capacities. The EREC contains around 953 ha, including native forest, pasture, commercial crops, and agricultural research plots. The surrounding region produces numerous crops, including forages, fruit, vegetables, and row crops (cotton, corn, soybeans, and peanuts). These high-value fruits and vegetables are typically irrigated, while the lowvalue forages and agronomic crops can be irrigated or rainfed.

\subsection{Prototype Development}

The IoT system prototypes were developed in 2017 with the capability to read and transmit data from either the Watermark 200SS (The Irrometer Company, Inc., Riverside, $\mathrm{CA}$ ) or the $\mathrm{ECH}_{2} \mathrm{O}$ EC-5 (METER Environment, Pullman, WA) soil moisture sensors. The IoT systems were assembled using prototyping circuit boards and included inputs for up to four Watermark or EC-5 sensors (Figure 1). The main component of the two IoT system prototypes was the Particle
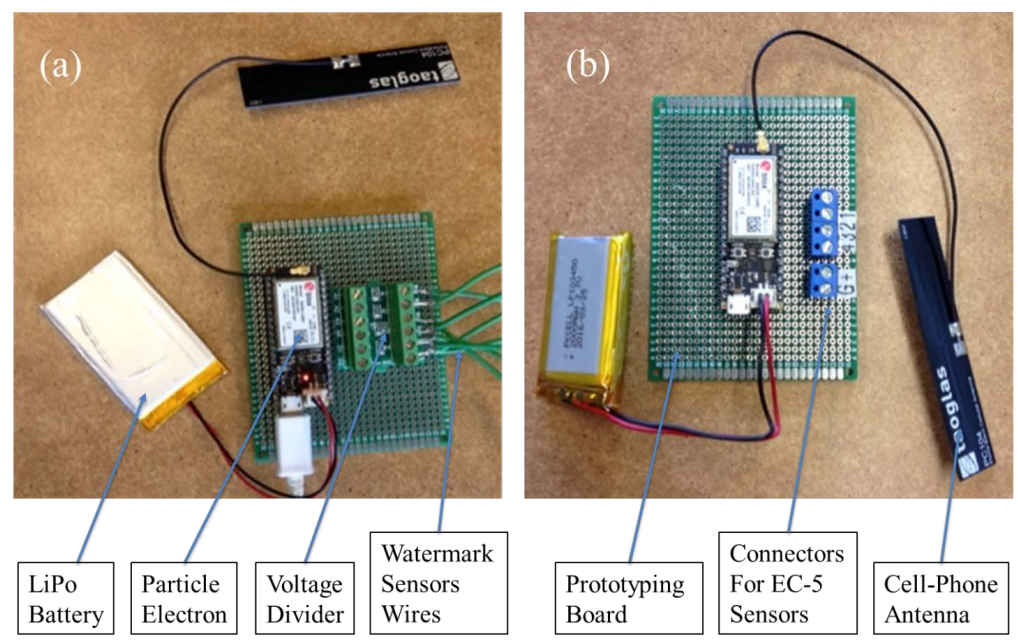

Figure 1. The printed circuit board prototypes are shown for the (a) Watermark and (b) EC-5 sensors. The Particle Electron device included a microcontroller and a cellular modem. 
Electron device (Particle Industries, Inc., San Francisco, CA), which was part of a Particle Electron 2G/3G (EMEA) Starter Kit

(https://store.particle.io/collections/dev-kits). These IoT system prototypes also included an antenna for a cellular modem, a LiPo battery to power the microcontroller, and sensor input connectors.

The Particle Electron device included an STM32F205 ARM Cortex M3 microcontroller with a $1 \mathrm{MB}$ flash, $128 \mathrm{MB}$ RAM, and a cellular modem [u-blox SARA U-series $(3 \mathrm{G})]$. The microcontroller had a total of 36 pins, including 28 GPIOs (D0-D13, A0-A13), TX/RX, 2 GNDs, VIN, VBAT, WKP, 3V3, and RST. The microcontroller operated at 3.3VDC with 12-bit Analog-to-Digital (A/D) inputs. The 12-bit resolution means that when using the analog inputs to make measurements, the output would result in an integer output (ranging from 0 to 4095). The cellular modem operated at frequencies of 850 and $1900 \mathrm{MHz}$, suitable for use in the Americas, Australia, and New Zealand. The Particle Electron kit also came with a SIM card with access to the 2G/3G cellular network service (available in over 100 countries). The microcontroller was Arduino-compatible and could be programmed using the Arduino language and libraries via the Particle Web Integrated Development Environment (Web IDE)

(https://www.particle.io/).

The Watermark and EC-5 sensors measure soil moisture in different ways. The Watermark sensor measures soil water tension using a solid-state electrical resistance sensor. Soil water tension changes with soil water content, and the Watermark sensor measures these changes using electrical resistance. The Watermark sensors produce an output ranging from 0 to 200; the $0 \mathrm{kPa}$ represents wet (saturated) soil and $200 \mathrm{kPa}$, air-dry soil. In this study, the sign of the output was reversed so that the output readings would make more sense for end-users. The range of output values from the sensor would then be $-200 \mathrm{kPa}$ (air-dry soil) to $0 \mathrm{kPa}$ (saturated soil). Therefore, as the soil dries, the sensor output readings from the Watermark would become more negative.

In contrast, The EC- 5 sensor determines volumetric water content (VWC) by measuring the soil dielectric constant using capacitance/frequency domain technology. The EC-5 produces an analog signal output, which is correlated to the current soil VWC. Therefore, to read the EC-5 sensor using a microcontroller or other datalogger, the procedure is to apply a known and regulated voltage to the sensor and then measure the output voltage [26]. The Watermark sensor can be read in a similar manner using a microcontroller. Similar to the EC-5, a known, regulated voltage is applied to the sensor and then the output voltage is measured. However, since output resistance is required, the input voltage must first pass through a voltage divider circuit [27]. In Figure 1(a), the sensor prototype for the Watermark sensors with the voltage divider is shown. The voltage divider circuit was constructed using a custom-made printed circuit board (PCB). This voltage divider PCB was built to accommodate four Watermark sensors. 


\subsection{Sensor Calibration}

As indicated earlier, when using the analog inputs from the microcontroller to make measurements, the output of the analog-to-digital converter (ADC) needs to be an integer in the range of 0 to 4095 . However, when measuring the Watermark sensors, the output is required in units of soil water tension $(\mathrm{kPa})$, and when measuring with the EC-5 sensors, the result is required in units of VWC $\left(\mathrm{m}^{3} \cdot \mathrm{m}^{-3}\right)$. Therefore, lab calibrations were conducted to convert the ADC output to soil water tension or VWC. For the Watermark calibration, sensors were installed inside soil containers with varying water content, ranging from air-dry to saturated soil (Figure 2(a)). Watermark sensor readings were taken using the microcontroller and a Watermark Handheld Meter (The Irrometer Company, Inc., Riverside, CA). For the EC-5 calibration, four EC-5 sensors were inserted inside a wide mouth Erlenmeyer flask (Figure 2(b)). The water level was changed in each flask to produce VWC outputs to simulate the range between air-dry to saturated soil. At each water level, the analog outputs from the EC-5 sensors were measured using the microcontroller and a ProCheck handheld meter (Meter Group, Pullman, WA).

\subsection{Laboratory Testing of Prototypes}

Once the prototypes were constructed, and the sensors were calibrated, a laboratory test was conducted to evaluate if the system was sensitive to soil moisture changes and assess the data communication system's reliability. Four Watermark sensors and four EC-5 sensors were placed into $250 \mathrm{~mL}$ beakers filled with soil (Figure 2(a)). The sensors were connected to the prototypes, and sensor readings were collected every hour. The soil containers were stored in an indoor laboratory and allowed to dry at ambient room temperature. When the soil was dry, water was added to each container bring it back to saturation. This process was repeated to create three soil drying cycles between early October and the end of November 2017. The data collected on an hourly basis during that time-period was transmitted to the ThingSpeak website (ThingSpeak.com) for storage and visualization. The data stored on the ThingSpeak website data could also be visualized on a cell phone using the ThingView App [26] [27].
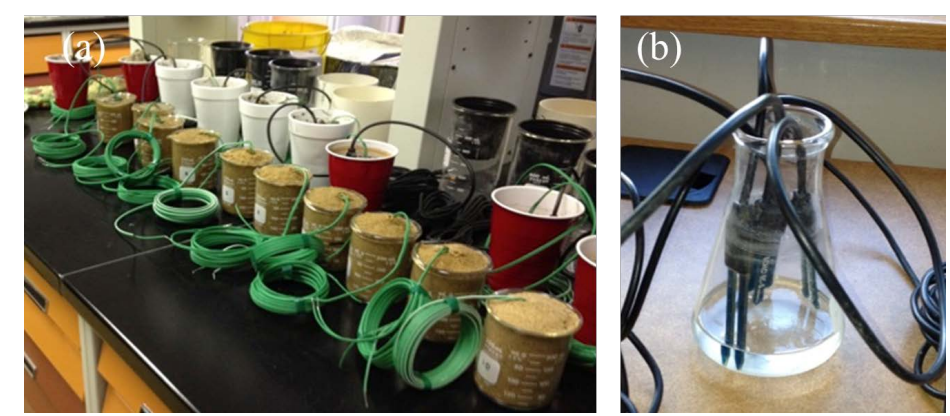

Figure 2. The (a) Watermark and (b) EC-5 sensors calibration procedure in the laboratory. 


\subsection{Development of PCB}

Once the laboratory experiments were conducted, the first step towards moving from the prototypes to mass production and field deployment was designing and fabricating PCBs to integrate the microcontroller with the sensors. The PCB for the Watermark and the EC-5 sensors were designed and manufactured in early 2018 using the Pad2Pad (https://www.pad2pad.com/) system (Figure 3). Pad2Pad provides free PCB design software and online ordering and manufacturing of the designed PCB boards. The Watermark and EC- 5 sensors PCB boards were constructed with connectors for up to four sensors. The voltage divider circuit was then integrated into the Watermark sensor PCB board. The Particle Electron device could be soldered directly to the $\mathrm{PCB}$, or two female 18-pin headers could be soldered to the PCB to allow easy removal and replacement of the Particle Electron device. The unit price of the PCB manufacturing decreases with quantity. For this study, an initial batch of 50 boards was ordered for a reasonable cost.

\subsection{Setup for Field Deployment}

The IoT soil moisture monitoring system component are shown in Figure 4. Since the system was intended to be installed in remote locations, the system contained an internal power supply of a 3.7 VDC, $2000 \mathrm{mAh}$ Lithium-Ion (LiPo) battery, recharged using a $6 \mathrm{~V}, 2 \mathrm{~W}$ externally mounted solar panel (Adafruit Industries, Inc., NY). The internal power supply system also included a USB/DC/Solar Lithium Ion/Polymer charger (Adafruit Industries, Inc., NY). This device is a solar charger controller that automatically uses the solar panel power when available to maintain or recharge the LiPo battery level.

The IoT soil moisture monitoring systems were housed in an enclosure for protection of all the electronic components. The enclosure was constructed from a 1.5 in $(38 \mathrm{~mm})$ PVC pipe. A PVC cap was glued to the back of the solar panel, which served to close the pipe while supporting the solar panel in a horizontal position. A $3 / 4$ in $(19 \mathrm{~mm})$ PVC pipe was attached at the other end of the enclosure to keep the electronics above the crop canopy. The sensor wires could be inserted inside the vertical pipe to protect the wires. Figure 4(b) shows that the Watermark sensors were attached to a $1 / 2$ in $(13 \mathrm{~mm})$ PVC pipes of different lengths, which facilitated field installation and removal of the sensors out of the field at the end of the growing season.
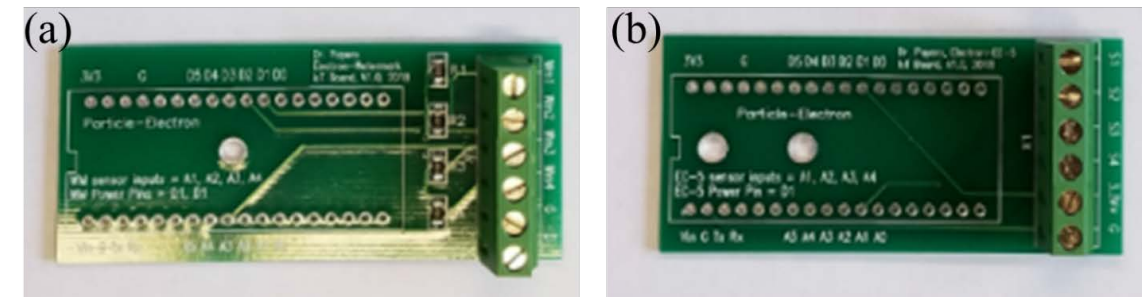

Figure 3. Printed circuit board for (a) the Watermark sensors and (b) the EC-5 sensors. 


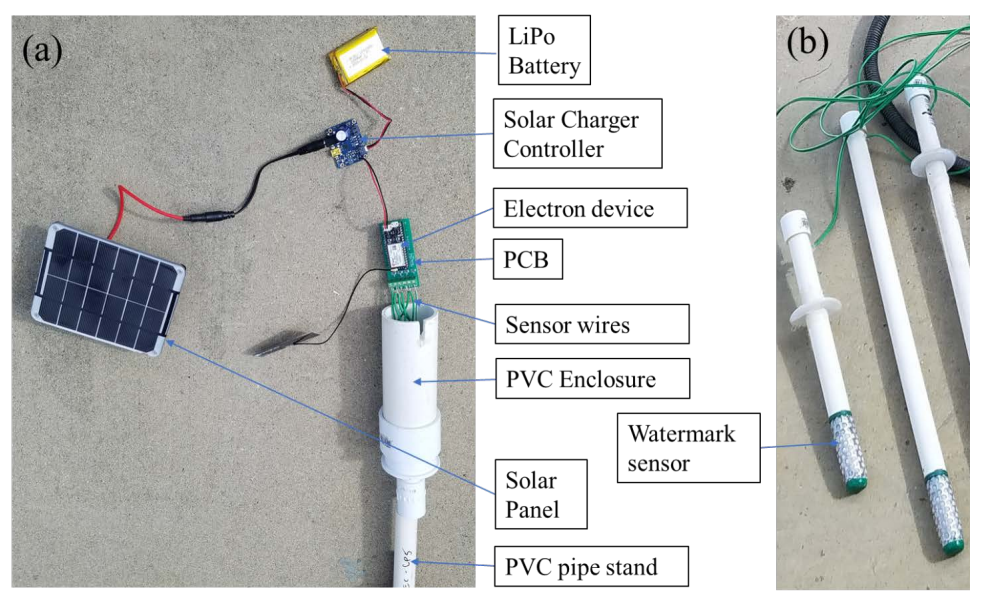

Figure 4. Soil moisture monitoring system (a) the components of the data logging and data transmission system and (b) the Watermark sensors attached to PVC pipes. The Particle Electron device includes a microcontroller and a cellular modem.

\subsection{Field Deployment}

In 2018, 2019, and 2020, cell-phone-based soil moisture monitoring systems were constructed and installed in approximately twenty fields in South Carolina. These fields were planted to various crops in commercial farms and research applications at the EREC. For example, Figure 5(a) shows the soil moisture monitoring system installed in a peanut field in Blackville, SC, in 2018. Due to cost, the IoT soil moisture monitoring systems installed in the field used the more economical and durable Watermark sensors. The Watermarks were also easier to install and remove from the field than the EC- 5 sensors. The sensors were installed in the soil profile at the following depths of $15,30,45$, and $60 \mathrm{~cm}$.

\subsection{System Updates and Modifications}

In 2019, although the soil moisture monitoring system was working as expected, there were concerns about the long-term availability of the $2 \mathrm{G} / 3 \mathrm{G}$ cellular networks the Particle Electron device was using in the United States. Therefore, the Particle Electron component was replaced with a Boron device (Particle Industries, Inc., San Francisco, CA). The Boron device supported Long Term Evolution (LTE) cellular technology and also offered legacy support for $2 \mathrm{G} / 3 \mathrm{G}$ cellular networks. However, the Boron device pin layout on the microcontroller and footprint were different compared to the Particle Electron device. The Watermark and EC-5 sensor PCBs (similar to the PCB shown in Figure 3) were modified and fabricated to accept the new Boron device.

Also, other changes and enhancements were made to enhance its affordability and ease of fabrication and installation. For example, the $2 \mathrm{~W}$ solar panel was replaced with a larger capacity $3.5 \mathrm{~W}, 6 \mathrm{~V} 583 \mathrm{~mA}$ Mini Solar Panel Module (Sunnytech, Amazon.com). The solar charger controller was also replaced with a DFR0264 solar charger (DFRobot, Digi-Key Part Number 1738-1177-ND). Instead of housing the electronics in a PVC pipe, a NEMA economy electronics 


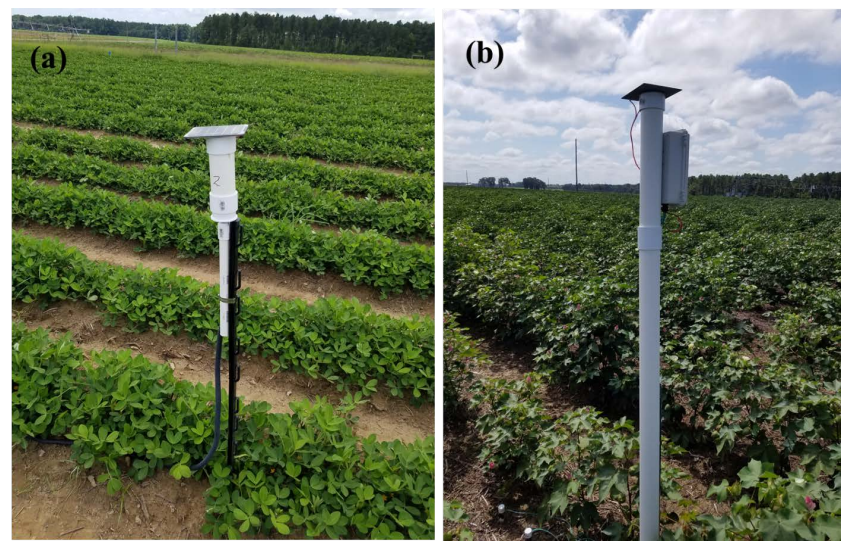

Figure 5. (a) The IoT soil moisture monitoring systems installed in a peanut field in 2018 and the updated (b) IoT soil moisture monitoring system installed in a cotton field in 2019.

box with a solid, weather-resistant door was added (BUD Industries, Amazon.com). The NEMA box was mounted to a 2 in (50 $\mathrm{mm}$ ) vertical PVC pipe and the solar panel was glued to a cap which was placed on top of the vertical pipe. The updated automated IoT soil moisture system was then installed in a cotton field in 2019 (Figure 5(b)).

\subsection{Cost of Monitoring System Components}

The unit prices and costs of the soil moisture monitoring system are shown in Table 1. These prices and costs were divided into the following components: original Particle Electron design, modified Boron design, sensors, data communication, and data storage/visualization. The parts needed to build the field setup (excluding the sensors) using the original Particle Electron design or the modified Boron design resulted in a similar cost of around US\$130.00. For both the original Particle Electron and the Boron design, the Particle Electron Starter Kit or Boron Starter Kit represented $54 \%$ of the total cost. The cost of four Watermark sensors was around US\$200.00, while four EC-5 sensors were approximately US\$500.00.

A cellular data plan was obtained and used to transmit the data from one field setup to the Internet was around US\$5.00/month (US\$60.00/year). The cost depended on the volume of data transmitted. The cost of data storage/visualization using ThingSpeak also depended on the number of channels and the volume of data sent to the system. For this study, ThingSpeak offered a free account, which came with some limitations to the number of channels and data volume, which would be sufficient for most users. They also provided educational and commercial licenses that offer more data storage and flexibility. An educational license was obtained for this project at a cost of US\$250/year. In this case, using ThingSpeak would be a developer cost and not a cost to the final user of the soil moisture monitoring system. Currently, there is no cost to visualizing the data on a cell phone using the ThingView App. 
Table 1. Cost of components of the watermark and EC5 soil moisture monitoring systems.

\begin{tabular}{|c|c|c|c|c|}
\hline Component & Item & Quantity & $\begin{array}{l}\text { Unit Price } \\
\text { (US\$) }\end{array}$ & $\begin{array}{c}\text { Total Cost } \\
\text { (US\$) }\end{array}$ \\
\hline \multirow{5}{*}{ Particle Electron design } & Particle Electron Starter Kit & 1 & $\$ 71.35$ & \\
\hline & Solar panel $(6 \mathrm{~V}, 2 \mathrm{~W})$ & 1 & $\$ 29.00$ & \\
\hline & Solar Charger Controller & 1 & $\$ 17.50$ & \\
\hline & PCB fabrication & 1 & $\$ 4.00$ & \\
\hline & PVC pipe \& Fittings & 1 & $\$ 10.00$ & $\$ 131.85$ \\
\hline \multirow{7}{*}{ Boron design } & Boron Starter Kit & 1 & $\$ 67.21$ & \\
\hline & LiPo battery & 1 & $\$ 12.50$ & \\
\hline & Enclosure & 1 & $\$ 12.70$ & \\
\hline & Solar panel $(6 \mathrm{~V}, 3.5 \mathrm{~W})$ & 1 & $\$ 12.99$ & \\
\hline & Solar charger controller & 1 & $\$ 4.90$ & \\
\hline & PCB fabrication & 1 & $\$ 4.00$ & \\
\hline & PVC pipe \& Fittings & 1 & $\$ 10.00$ & $\$ 124.30$ \\
\hline \multirow{2}{*}{ Sensors } & Watermark & 4 & $\$ 50.00$ & $\$ 200.00$ \\
\hline & EC-5 & 4 & $\$ 125.00$ & $\$ 500.00$ \\
\hline Data communication & Cell phone data plan & 1 & $\$ 60 /$ year & $\$ 60 /$ year \\
\hline Data storage/ & ThingSpeak annual fee & 1 & $0-\$ 250$ & $0-\$ 250$ \\
\hline Visualization & ThingView App annual fee & 1 & Free & Free \\
\hline
\end{tabular}

\section{Results and Discussion}

\subsection{Laboratory Sensor Calibration}

The results of laboratory sensor calibration for the Watermark and EC-5 sensors are shown in Figure 6 and Figure 7, respectively. For the Watermark sensors, relationship between ADC output of the Particle Electron device and soil water potential was explained by a $4^{\text {th }}$ degree non-linear polynomial $\left(\mathrm{R}^{2}=0.997, p<\right.$ $0.01)$. The soil water potential measured by the Watermark Handheld Meter had a range of -200 to $0 \mathrm{kPa}$ (Figure 6(a)). For the same range of soil water potential values, there was a strong linear relationship $\left(\mathrm{R}^{2}=0.988, p<0.01\right)$ between the resistance measured with the microcontroller and the soil water potential measured with the Watermark Handheld Meter (Figure 6(b)). Figure 6 also showed that despite the Watermark Handheld Meter range is limited 0 to $200 \mathrm{kPa}$ (the range is 0 to $-200 \mathrm{kPa}$ in Figure 6), the ADC output or resistance measured by the microcontroller registered values were sensitive even under dry soil conditions. However, to maintain consistency with the Watermark sensor manufacturers recommendations, the output of the microcontroller was limited to the range between 0 and $-200 \mathrm{kPa}$.

Similarly, there was an excellent linear relationship $\left(\mathrm{R}^{2}=0.994, p<.01\right)$ between the ADC output of the microcontroller and the VWC measured with the 

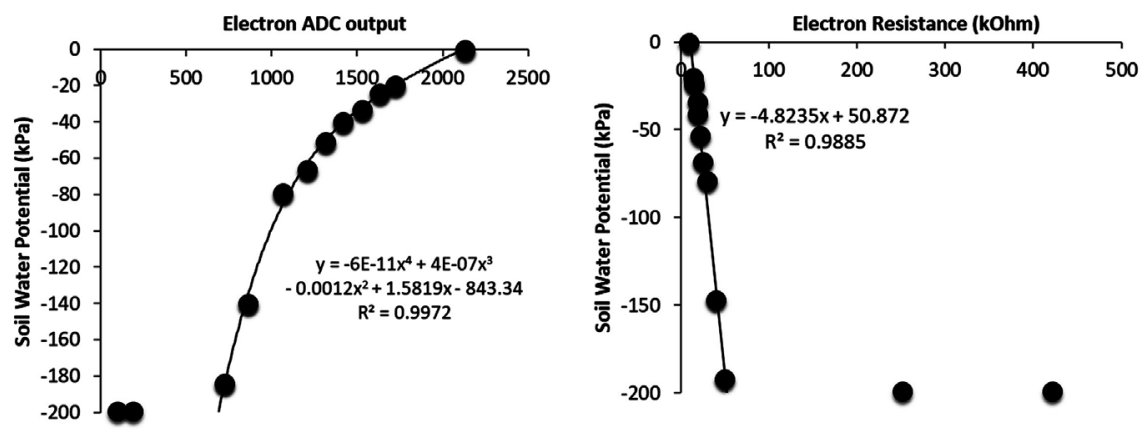

Particle Electron - Watermark Calibration.

(a)

(b)

Figure 6. Relationship between (a) analog to digital converter (ADC) output and soil water potential, and (b) resistance and soil water potential measured using the Watermark sensors.

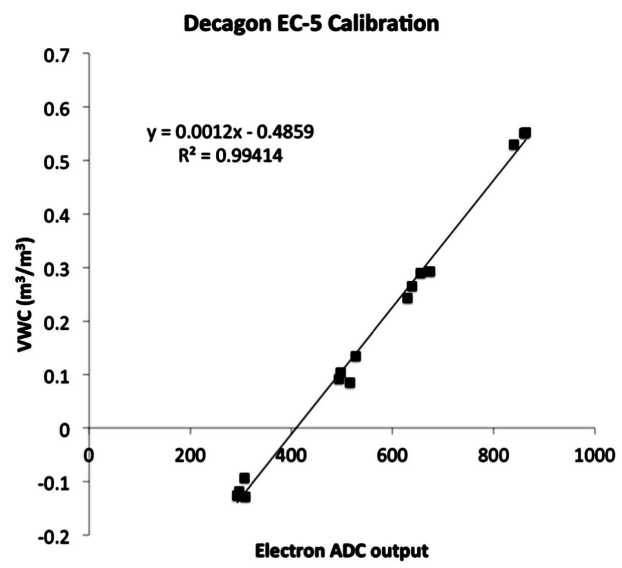

Figure 7. The relationship between particle electron Analog to Digital Converter (ADC) output and Volumetric Water Content (VWC) reading using the EC-5 sensors.

ProCheck Handheld Meter (Figure 7). The linear equation was then used to convert the microcontroller's output (resistance, $\mathrm{kOhm}$ ) to either soil water potential $(\mathrm{kPa})$ or VWC values (Figure 6$)$.

\subsection{Particle Electron Device Prototype Laboratory Test}

The study results conducted with the Particle Electron device prototype during three soil drying cycles are shown in Figure 8 for the Watermark sensors and Figure 9 for the EC-5 sensors. The screenshots from the ThingSpeak website (a single channel is shown), which illustrated sensor data visualization (Figure 8 and Figure 9). The soil moisture readings from the Watermark and EC-5 sensors followed a similar but the expected trend during the soil drying cycles followed by wetting after water was added to the soil. For the duration of the test, the cellular data connection with the sensors was very reliable, and the hardware/software components operated as expected. Afterwards, the PCBs were fabricated and assembled for field deployment. 
Updated: about an hour ago

Last entry: about an hour ago

Entries: 515
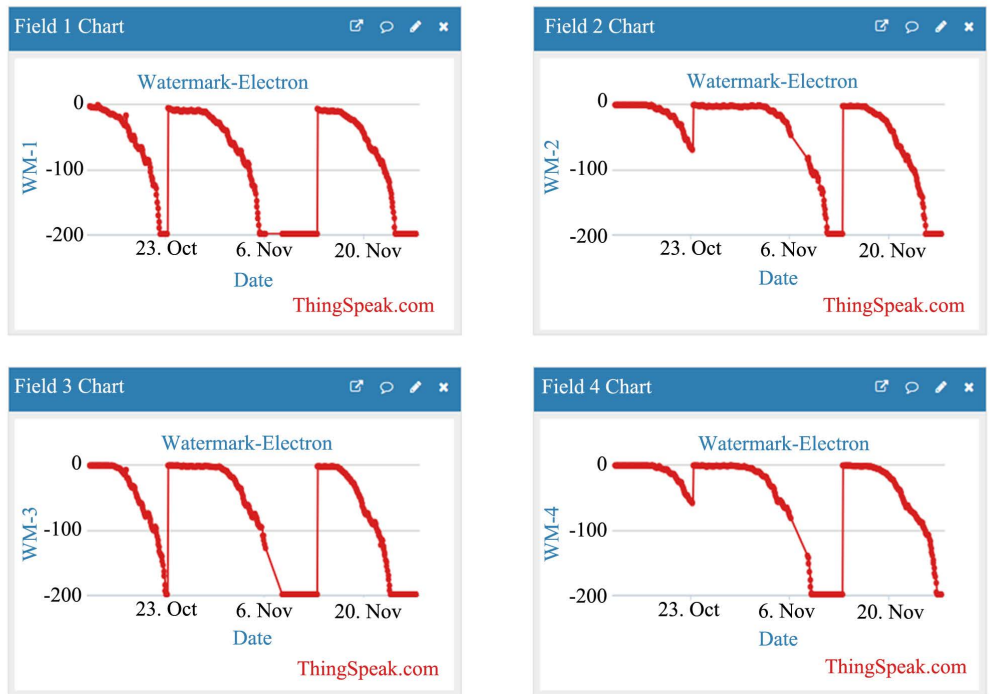

Figure 8. The Volumetric Water Content (VWC) of soil collected during 3 drying cycles in the laboratory using four Watermark sensors.

\section{$\square$ ThingSpeak ${ }^{\mathrm{TM}}$ Channels- Apps Community Support -}

\section{Last entry: about an hour ago}

Entries: 515
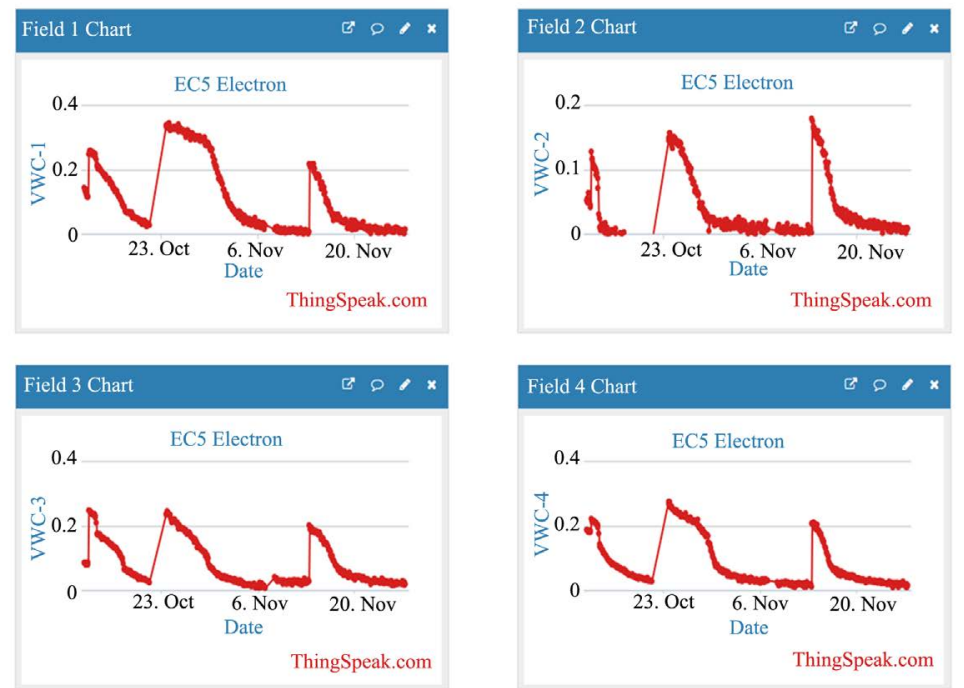

Figure 9. The Volumetric Water Content (VWC) of soil collected during 3 drying cycles in the laboratoryusing four Decagon EC-5 sensors.

\subsection{Field Deployment and Testing of Soil Moisture Monitoring System}

As indicated earlier, in 2018, 2019, and 2020, cell-phone-based soil moisture monitoring systems were constructed and installed in twenty fields with varying cropping systems in South Carolina. The objective of this study was to determine 
system reliability and performance under field conditions over time. The intent of this part of the study was to demonstrate the systems long-term reliability in the field; therefore, soil moisture readings were collected from a grapevine orchard site in Pickens County, SC over three growing seasons (Figure 10). In the orchard site, a soil moisture monitoring system with four Watermark sensors was installed at depths of 15, 30,45, and $60 \mathrm{~cm}$ in July 2018. The hourly VWC data collected during the crop growing season is shown in Figure 10. These results showed that the soil moisture monitoring system operated robustly and collected data, without loss, for nearly three years, demonstrating accuracy and reliability of the system.

Similarly, Figure 11 showed the VWC collected using the four EC-5 sensors installed in a rye cover crop in Barnwell County, SC. Figure 11(a) shows a seasonal trend of data collected every two hours from Dec 2017 to March 2018. TheVWC data collected using the EC-5 sensor was eratic compared to the Watermark sensor data. The EC-5 sensor VWC data over a 5-day period showed diurnal trend for all soil depths with VWC increasing in the morning hours and decreasing later in the day (Figure 11(b)). This diurnal effect on the EC-5 soil moisture readings suggested a potential temperature sensitivity of the sensors. However, the pattern was similar across all depths. The trend could have also resulted from other environmental issues affecting the actual VWC. Other potential factors affecting VWC could include presence of early morning dew (typical in the study area during the growing season) or upward movement of water
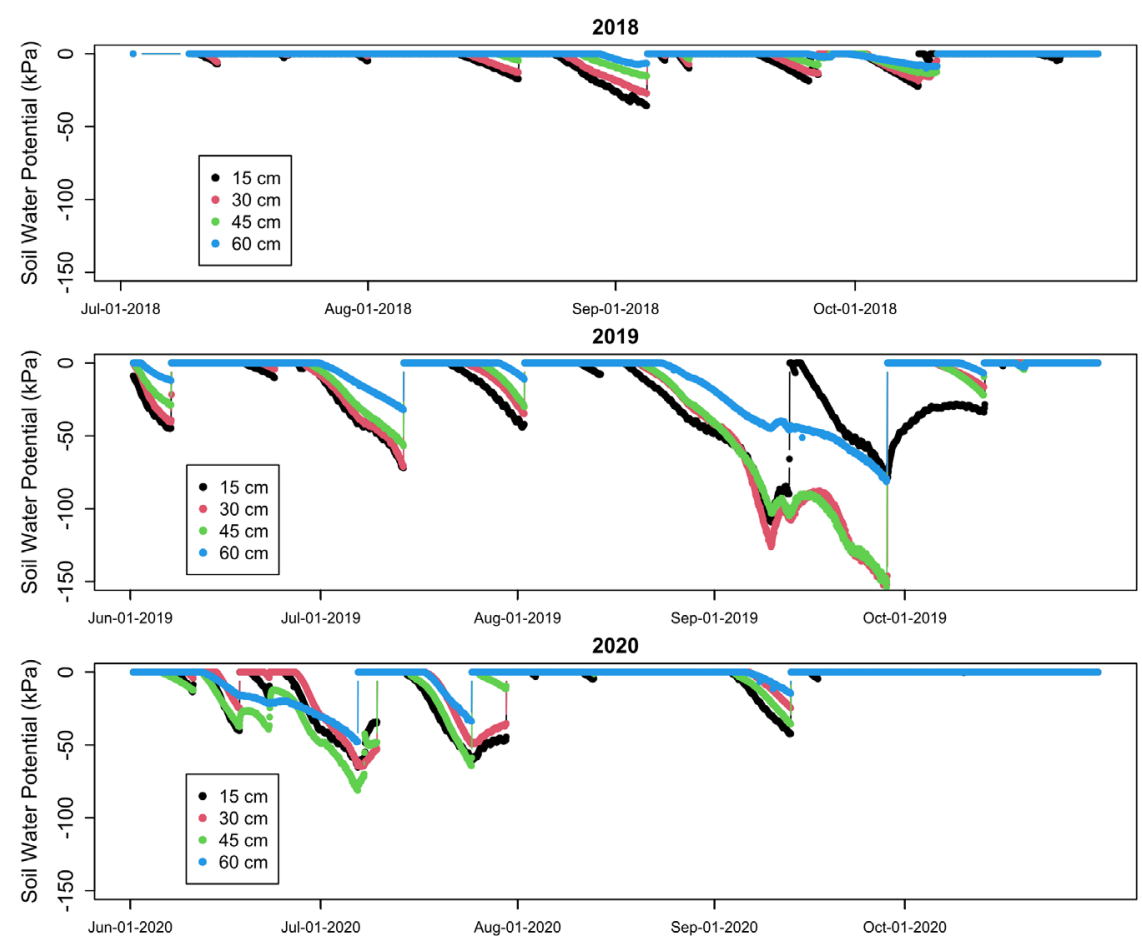

Figure 10. Hourly soil water potential collected in 2018, 2019, and 2020 with four Watermark sensors installed in a grapevine orchard in South Carolina. 


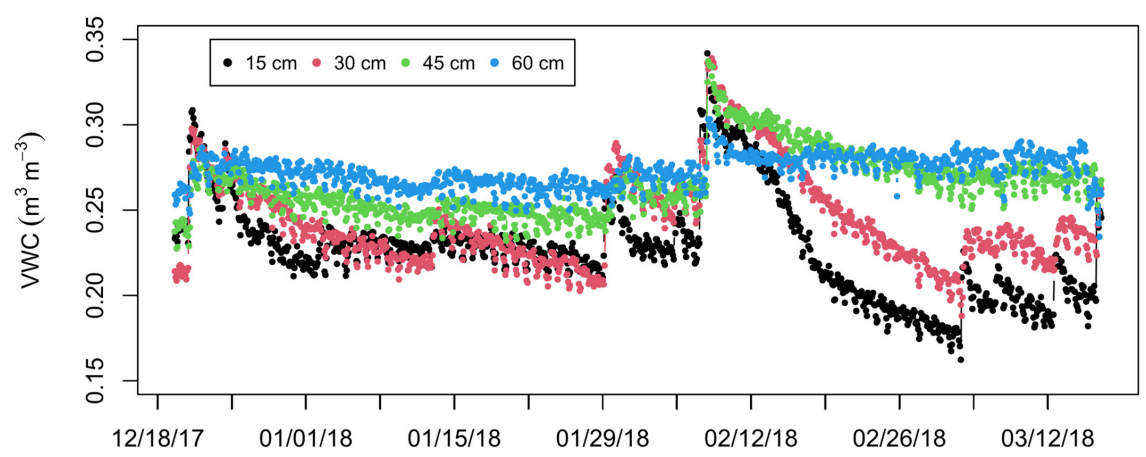

(a)

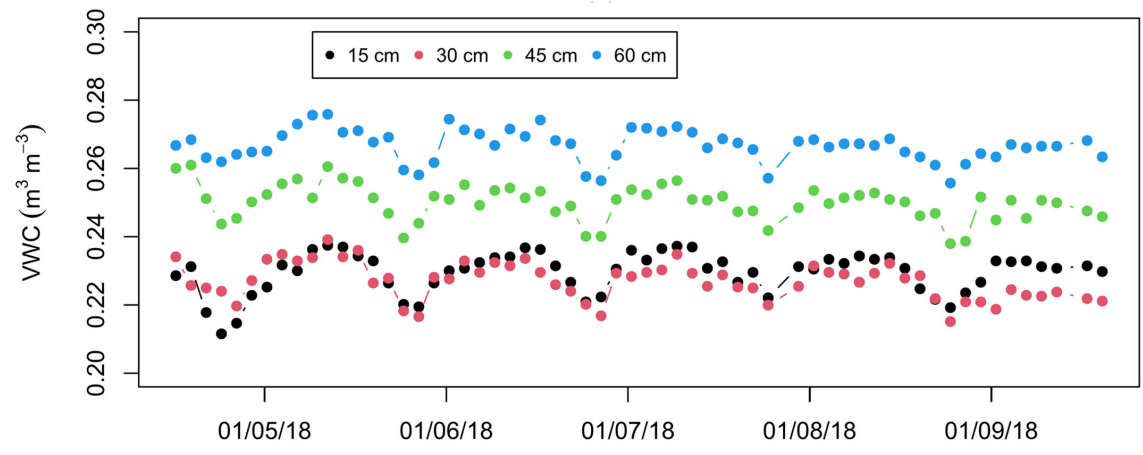

(b)

Figure 11. The Volumetric water content (VWC) collected using four EC-5 sensors installed at 15, 30, 45, and $60 \mathrm{~cm}$ depths in a rye cover crop in South Carolina. The seasonal trend of VWC collected during the cover crop cycle from Dec 2017 to March 2018 are shown in (a) and the diurnal effects on VWC (five day period) are also shown in (b). (a) EC-5 sensors, 2017-2018; (b) EC-5 sensors.

in the soil profile due to a fluctuating soil water table. However, the EC-5 sensor measurements accurately represented the day-to-day changes in VWC which is adequate for scheduling day-to-day irrigation decisions.

\section{Conclusion}

In this project, the IoT systems for soil moisture monitoring were designed, fabricated and deployed to the field. The systems developed utilized either the Particle Electron or Particle Proton devices for data storage and transmission (Arduino-compatible microcontroller and a cellular modem). Based on the results from this research, these IoT systems can be used effectively to collect and transmit soil moisture data from either a Watermark or EC-5 sensors. The Watermark and EC- 5 are commercially available soil moisture sensors typically used in irrigation scheduling. The IoT systems also allowed data visualization in real-time on a computer or cell phone. The cost of components for building the IoT system (minus sensor cost) was around US\$130.00. Over the last three years $(2018,2019$, and 2020), the IoT systems have been deployed successfully in the field and used to monitor and collect soil moisture data several research field trials and commercial farms in South Carolina. The IoT systems have shown to be robust and reliable under South Carolina field conditions. However, the IoT 
systems depend on accessible and reliable cell phone service near the site of monitoring which could be a significant limitation in remote areas. The IoT systems developed and deployed in the project are being demonstrated across commercial farms in South Carolina to promote the practice of using real-time soil moisture data for irrigation scheduling decisions.

\section{Acknowledgements}

Technical Contribution No. 6979 of the Clemson University Experiment Station. This material is based upon work supported by NIFA/USDA project SC-1700593 and SC-1700592. USDA-NRCS Projects 69-3A75-17-274 and NR203A750013G010 also provided additional funding.

\section{Conflicts of Interest}

The authors declare no conflicts of interest regarding the publication of this paper.

\section{References}

[1] Ochsner, T.E., Cosh, M.H., Cuenca, R.H., Dorigo, W.A., Draper, C.S., Hagimoto, Y., et al. (2013) State of the Art in Large-Scale Soil Moisture Monitoring. Soil Science Society of America Journal, 77, 1888-1919. https://doi.org/10.2136/sssaj2013.03.0093

[2] Smith, A.B., Walker, J.P., Western, A.W., Young, R.I., Ellett, K.M., Pipunic, R.C., et al. (2012) The Murrumbidgee Soil Moisture Monitoring Network Data Set. Water Resources Research, 48, Article No. W07701. https://doi.org/10.1029/2012WR011976

[3] Martín, A., Ibáñez, S., Baixauli, C., Blanc, S. and Anquela, A.B. (2020) Multi-Constellation GNSS Interferometric Reflectometry with Mass-Market Sensors as a Solution for Soil Moisture Monitoring. Hydrology and Earth System Sciences, 24, 3573-3582. https://doi.org/10.5194/hess-24-3573-2020

[4] Wang, L. and Qu, J.J. (2009) Satellite Remote Sensing Applications for Surface Soil Moisture Monitoring: A Review. Frontiers of Earth Science in China, 3, 237-247. https://doi.org/10.1007/s11707-009-0023-7

[5] Kodikara, J., Rajeev, P., Chan, D. and Gallage, C. (2014) Soil Moisture Monitoring at the Field Scale Using Neutron Probe. Canadian Geotechnical Journal, 51, 332-345. https://doi.org/10.1139/cgj-2012-0113

[6] Herkelrath, W.N., Hamburg, S.P. and Murphy, F. (1991) Automatic, Real-Time Monitoring of Soil Moisture in a Remote Field Area with Time Domain Reflectometry. Water Resources Research, 27, 857-864. https://doi.org/10.1029/91WR00311

[7] Skierucha, W., Wilczek, A., Szypłowska, A., Sławiński, C. and Lamorski, K. (2012) A TDR-Based Soil Moisture Monitoring System with Simultaneous Measurement of Soil Temperature and Electrical Conductivity. Sensors, 12, 13545-13566. https://doi.org/10.3390/s121013545

[8] Berthelin, R., Rinderer, M., Andreo, B., Baker, A., Kilian, D., Leonhardt, G., et al. (2020) A Soil Moisture Monitoring Network to Characterize Karstic Recharge and Evapotranspiration at Five Representative Sites Across the Globe. Geoscientific Instrumentation, Methods and Data Systems, 9, 11-23. 
https://doi.org/10.5194/gi-9-11-2020

[9] Fares, A. and Alva, A.K. (2000) Evaluation of Capacitance Probes for Optimal Irrigation of Citrus through Soil Moisture Monitoring in an Entisol Profile. Irrigation Science, 19, 57-64. https://doi.org/10.1007/s002710050001

[10] Osenga, E.C., Arnott, J.C., Endsley, K.A. and Katzenberger, J.W. (2019) Bioclimatic and Soil Moisture Monitoring Across Elevation in a Mountain Watershed: Opportunities for Research and Resource Management. Water Resources Research, 55, 2493-2503. https://doi.org/10.1029/2018WR023653

[11] Wyatt, B.M., Ochsner, T.E., Fiebrich, C.A., Neel, C.R. and Wallace, D.S. (2017) Useful Drainage Estimates Obtained from a Large-Scale Soil Moisture Monitoring Network by Applying the Unit-Gradient Assumption. Vadose Zone Journal, 16, 1-15. https://doi.org/10.2136/vzj2017.01.0016

[12] Köhli, M., Schrön, M., Zreda, M., Schmidt, U., Dietrich, P. and Zacharias, S. (2015) Footprint Characteristics Revised for Field-Scale Soil Moisture Monitoring with Cosmic-Ray Neutrons. Water Resources Research, 51, 5772-5790. https://doi.org/10.1002/2015WR017169

[13] Qiao, X., Khalilian, A., Payero, J.O., Maja, J.M., Privette, C. and Han, Y.J. (2016) Evaluating Reflected GPS Signal as a Potential Tool for Cotton Irrigation Scheduling. Advances in Remote Sensing, 5, 157-167. http://doi.org/10.4236/ars.2016.53013

[14] Sayde, C., Gregory, C., Gil-Rodriguez, M., Tufillaro, N., Tyler, S., Van de Giesen, N., et al. (2010) Feasibility of Soil Moisture Monitoring with Heated Fiber Optics. Water Resources Research, 46, Article No. W06201. https://doi.org/10.1029/2009WR007846

[15] Striegl, A.M. and Loheide, S.P. (2012) Heated Distributed Temperature Sensing for Field Scale Soil Moisture Monitoring. Groundwater, 50, 340-347. https://doi.org/10.1111/j.1745-6584.2012.00928.x

[16] Sourbeer, J.J. and Loheide, S.P. (2016) Obstacles to Long-Term Soil Moisture Monitoring with Heated Distributed Temperature Sensing. Hydrological Processes, 30, 1017-1035. https://doi.org/10.1002/hyp.10615

[17] Bauer-Marschallinger, B., Freeman, V., Cao, S., Paulik, C., Schaufler, S., Stachl, T., et al. (2019) Toward Global Soil Moisture Monitoring with Sentinel-1: Harnessing Assets and Overcoming Obstacles. IEEE Transactions on Geoscience and Remote Sensing, 57, 520-539. https://doi.org/10.1109/TGRS.2018.2858004

[18] Zhang, F., Zhang, L.W., Shi, J.J. and Huang, J.F. (2014) Soil Moisture Monitoring Based On Land Surface Temperature-Vegetation Index Space Derived from MODIS Data. Pedosphere, 24, 450-460. https://doi.org/10.1016/S1002-0160(14)60031-X

[19] International Telecommunication Union (2013) Overview of the Internet of Things. ITU-T Y-Series Recommendations (Y.2060), Global Information Infrastructure, Internet Protocol Aspects and Next-generation Networks. International Telecommunication Union, Geneva, $22 \mathrm{p}$.

[20] Chung, W.Y., Villaverde, J.F. and Tan, J. (2013) Wireless Sensor Network Based Soil Moisture Monitoring System Design. 2013 Federated Conference on Computer Science and Information Systems, Kraków, 8-11 September 2013, 79-82.

[21] Zhang, X., Zhang, J., Li, L., Zhang, Y. and Yang, G. (2017) Monitoring Citrus Soil Moisture and Nutrients Using an IoT Based System. Sensors, 17, Article No. 447. https://doi.org/10.3390/s17030447

[22] Athani, S., Tejeshwar, C.H., Patil, P., Patil, M.M. and Kulkarni, R (2017) Soil Moisture Monitoring Using Iot Enabled Arduino Sensors with Neural Networks for Im- 
proving Soil Management for Farmers and Predict Seasonal Rainfall for Planning Future Harvest in North Karnataka-India. Proceedings of the International Conference on I-SMAC (IoT in Social, Mobile, Analytics and Cloud) (I-SMAC 2017), Palladam, 10-11 February 2017, 43-48. https://doi.org/10.1109/I-SMAC.2017.8058385

[23] Kodali, R.K. and Sahu, A. (2016) An IoT Based Soil Moisture Monitoring on Losant Platform. Proceedings of the 2016 2nd International Conference on Contemporary Computing and Informatics (IC31), Noida, 14-17 December 2016, 764-768.

https://doi.org/10.1109/IC3I.2016.7918063

[24] Ezhilazhahi, E.M. and Bhuvaneswari, P.T.V. (2017) IoT Enabled Plant Soil Moisture Monitoring Using Wireless Sensor Networks. Proceedings of the 2017 IEEE Third International Conference on Sensing, Signal Processing and Security (ICSSS), Chennai, 4-5 May 2017, 345-349. https://doi.org/10.1109/SSPS.2017.8071618

[25] Nagahage, E., Nagahage, I. and Fujino, T. (2019) Calibration and Validation of a Low-Cost Capacitive Moisture Sensor to Integrate the Automated Soil Moisture Monitoring System. Agriculture, 9, Article No. 141.

https://doi.org/10.3390/agriculture9070141

[26] Payero, J.O., Nafchi, A.M., Davis, R. and Khalilian, A. (2017) An Arduino-Based Wireless Sensor Network for Soil Moisture Monitoring Using Decagon EC-5 Sensors. Open Journal of Soil Science, 7, 288-300.

https://doi.org/10.4236/ojss.2017.710021

[27] Payero, J.O., Nafchi, A.M., Khalilian, A., Qiao, X. and Davis, R. (2017) Development of a Low-Cost Internet-Of-Things (IoT) System for Monitoring Soil Water Potential Using Watermark 200SS Sensors. Advances in Internet of Things, 7, 71-86. https://doi.org/10.4236/ait.2017.73005

[28] U.S. Climate Data (2020) Climate Blackville-South Carolina. https://www.usclimatedata.com/climate/blackville/south-carolina/united-states/ussc 0025 